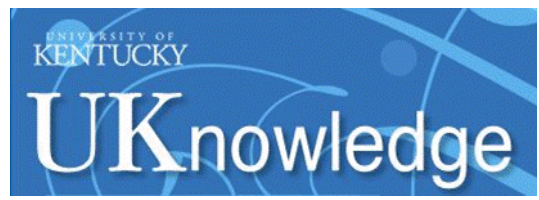

University of Kentucky

UKnowledge

\title{
A Systematic Study on the Effects of Dimensional and Materials Tolerances on Permanent Magnet Synchronous Machines Based on the IEEE Std 1812
}

\author{
Narges Taran \\ University of Kentucky, narges.taran@uky.edu \\ Vandana Rallabandi \\ University of Kentucky, vandana.rallabandi@uky.edu \\ Dan M. Ionel \\ University of Kentucky, dan.ionel@uky.edu \\ Ping Zhou \\ ANSYS, Inc. \\ Mark Theile \\ Regal Beloit Corporation, Australia \\ Follow this and additional works at: https://uknowledge.uky.edu/peik_facpub \\ 2 next page for additional authors \\ Part of the Power and Energy Commons
}

Right click to open a feedback form in a new tab to let us know how this document benefits you.

\section{Repository Citation}

Taran, Narges; Rallabandi, Vandana; Ionel, Dan M.; Zhou, Ping; Theile, Mark; and Heins, Greg, "A Systematic Study on the Effects of Dimensional and Materials Tolerances on Permanent Magnet Synchronous Machines Based on the IEEE Std 1812" (2019). Power and Energy Institute of Kentucky Faculty Publications. 26.

https://uknowledge.uky.edu/peik_facpub/26

This Article is brought to you for free and open access by the Power and Energy Institute of Kentucky at UKnowledge. It has been accepted for inclusion in Power and Energy Institute of Kentucky Faculty Publications by an authorized administrator of UKnowledge. For more information, please contact UKnowledge@lsv.uky.edu. 


\title{
A Systematic Study on the Effects of Dimensional and Materials Tolerances on Permanent Magnet Synchronous Machines Based on the IEEE Std 1812
}

\author{
Digital Object Identifier (DOI) \\ https://doi.org/10.1109/TIA.2018.2877144
}

\section{Notes/Citation Information}

Published in IEEE Transactions on Industry Applications, v. 55, issue 2.

(C) 2019 IEEE Copyright Notice. "Personal use of this material is permitted. Permission from IEEE must be obtained for all other uses, in any current or future media, including reprinting/republishing this material for advertising or promotional purposes,creating new collective works, for resale or redistribution to servers or lists, or reuse of any copyrighted component of this work in other works."

The document available for download is the authors' manuscript version that is accepted for publication. The final published version is copyrighted by IEEE and available as: N. Taran, V. Rallabandi, D. M. Ionel, P. Zhou, M. Thiele and G. Heins, "A Systematic Study on the Effects of Dimensional and Materials Tolerances on Permanent Magnet Synchronous Machines Based on the IEEE Std 1812," IEEE Transactions on Industry Applications, vol. 55, no. 2, pp. 1360-1371, March-April 2019. doi: 10.1109/ TIA.2018.28771

Authors

Narges Taran, Vandana Rallabandi, Dan M. Ionel, Ping Zhou, Mark Theile, and Greg Heins 


\title{
A Systematic Study on the Effects of Dimensional and Materials Tolerances on PM Synchronous Machines based on the IEEE Std 1812
}

\author{
Narges Taran ${ }^{1}$, Vandana Rallabandi ${ }^{1}$, Dan M. Ionel ${ }^{1}$, Ping Zhou ${ }^{2}$, Mark Theile ${ }^{3}$, and Greg Heins ${ }^{3}$ \\ ${ }^{1}$ Department of Electrical and Computer Engineering, University of Kentucky, Lexington, KY, USA \\ narges.taran@uky.edu, vandana.rallabandi@uky.edu,dan.ionel@uky.edu \\ ${ }^{2}$ ANSYS, Inc., Pittsburgh, PA, USA, ping.zhou@ansys.com \\ ${ }^{3}$ Regal Beloit Corporation, Rowville, VIC, Australia, mark.thiele@ regalbeloit.com, greg.heins@ regalbeloit.com
}

\begin{abstract}
In the process of designing and manufacturing an electrical machine, a systematic study of dimensional and material tolerances is of the utmost importance. This paper proposes a systematic method by which the effect of design specification variations on PM synchronous machine performance may be identified and quantified. The method combines design of experiments (DOE) techniques, open-circuit and short-circuit physical measurements and virtual test simulations conducted based on the recently approved IEEE Std 1812 testing guide. Three case studies, two provided by a spoke-type PM radial field machine configuration, in two designs with different electromagnetic loading, and an axial flux PM machine are discussed. It is shown that based on the output performance, out of specification tolerances for magnet remanence, steel grade, as well as dimensional variables, and stator to rotor eccentricity, may be identified under certain conditions. It is also exemplified that the ratings, magnetic loading, and configuration of the machine play critical roles and should be thoroughly considered as part of the studies.
\end{abstract}

Index Terms-Electric machine, manufacturing, tolerances, design of experiments, DOE, sensitivity analysis, open-circuit, short-circuit, tests, IEEE Std 1812, permanent magnet synchronous motor, axial flux, spoke-type.

\section{INTRODUCTION}

The systematic study of manufacturing tolerances for the design variables and material properties is essential for the successful development, prototyping, and production of electric machines [1]. Tolerances yield inevitable variations of output performance indices such as torque, losses, and efficiency. Establishing, under these conditions, the input to output system relationships is vital in order to ensure that performance is maintained within the specified limits around nominal values, and that, on the other hand, should these limits be exceeded, the root causes are traceable in terms of geometrical variables and/or material properties.

The subject matter is of great interest to the industry, but only relatively few papers have been published on related topics. Furthermore, most of publications study the effects of manufacturing tolerances on only one performance index. Earlier examples for permanent magnet (PM) machines include the use of a stochastic response surface method (RSM) for torque output studies [2]. The effects of manufacturing variations were examined through screening design of experiments (DOE) studies and RSM in order to identify the most Authors' manuscript version. The final published version is copyrighted by IEEE and available as: N. Taran, V. Rallabandi, D. M. Ionel, P. Zhou, M. Thiele and G. Heins, "A Systematic Study on the Effects of Dimensional and Materials Tolerances on Permanent Magnet Synchronous Machines Based on the IEEE Std 1812," IEEE Transactions on Industry Applications, vol. 55, no. 2, pp. 1360-1371, March-April 2019. doi: 10.1109/TIA.2018.2877144 (O2019 IEEE Copyright Notice. "Personal use of this material is permitted. Permission from IEEE must be obtained for all other uses, in any current or future media, including reprinting/republishing this material for advertising or promotional purposes, creating new collective works, for resale or redistribution to servers or lists, or reuse of any copyrighted component of this work in other works." important design variables affecting the performance [3]. More recently, computational estimations of the cogging torque for interior PM (IPM) machines were reported in [4] and the effect of geometrical asymmetries, caused by manufacturing variations, on cogging torque in surface mounted PM (SPM) machines was explored in [5]. Other studies, such as [6][9], also discuss the impact of deviations on torque ripple and cogging torque. The influence of manufacturing tolerances on other performance indices, such as the electromotive force (EMF), and on the air-gap flux density, was investigated for example in [10] and [11], respectively.

The research reported in the current paper, which is an extended follow up to a previous conference publication by the same group of authors [12], brings further contributions to the subject matter by specifically considering the performance indices as defined and evaluated through the procedures incorporated in the recently approved IEEE Std 1812 testing guide for synchronous PM machines [13]. A main objective of the current study is to establish if out of specification tolerances for the main dimensional variables and magnetic material properties may be traced just through a combination of IEEE Std 1812 tests and sensitivity analysis, both in case of early development prototypes as well as for manufactured products. In particular, the standardized open-circuit and shortcircuit tests are considered, as these are the most straightforward experiments, requiring only an external driving machine and standard electric measurement instrumentation, and are independent of any power electronics controls employed for machine operation in a specific application.

Two case studies are provided for a radial flux, concentrated winding, spoke-type rotor machine design (Fig. 1) for which the manufacturing tolerances of the many geometrical independent variables and the variations of magnetic materials properties are systematically examined. The work involved comprehensive large-scale computational studies conducted with previously experimentally validated high-fidelity finite element analysis (FEA) models implemented in the ANSYS Maxwell software, which is widely used both in industry and academia [14]. The motor performance is simulated with these FEA models according to the test procedures described in the IEEE Std 1812. This approach, referred to as virtual tests, was preferred in order to enable a design of virtual 


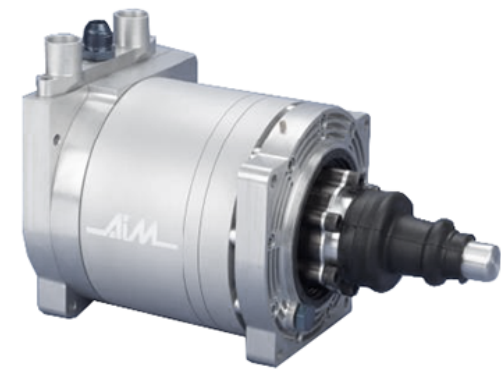

Figure 1. IPM spoke-type motor (100 hp) with rare earth magnets for Formula E racing cars. Photo courtesy of Equipmake, Ltd.

experiments study with thirteen independent variables and three outputs that requires hundreds of model variations within the prescribed limits. This type of study is more relevant to early developments efforts that are typically focused on concept demonstration and employ only a reduced number of physical prototypes, rather than to production level processes, which are subject to very rigorous manufacturing quality control.

A third case study is based on an axial flux PM (AFPM) machine (Fig. 2) and includes experiments performed with the same stator and rotor units for which all geometrical dimensions and magnetic material properties were carefully selected as close as possible to nominal values. In this case only the static eccentricity, which is an inherent typical outcome of stacked-up mechanical tolerances, is varied in a controlled manner through a special test fixture and measurements performed according to IEEE Std 1812. This last case study is more relevant to production processes and, as such, the examples included in the paper cover a wide range of situations.

The next section of the paper reviews the IEEE Std 1812 testing guide procedures considered for the study. Section III further elaborates on the case studies. Then, in the following section, the sensitivity of performance indices to the design variables is predicted based on analytical equations. DOE studies based on virtual test simulations and experimental analysis are reported in sections V and VI, respectively. The last two sections are devoted to discussions and conclusions.

\section{IEEE 1812 TeSTING Guide: OPEN-CiRCUIT AND SHORT-CIRCUIT TESTS}

The newly approved IEEE Std 1812 testing guide contains general instructions for determining the performance characteristics of PM machines. The guide includes steady-state tests for open-circuit, short-circuit, load, and thermal performance, and transient tests for retardation and sudden short-circuit [13]. Virtual tests i.e. high fidelity FEA simulations, for the spoke-type PM machine and experimental measurements for the AFPM machine are conducted under the specified IEEE Std 1812 conditions.

According to the IEEE Std 1812 testing guide, section 4.3, the short-circuit test is conducted using a shorting switch and an optional external limiting impedance. The current, $I_{s c}$, is measured after the steady-state short-circuit condition

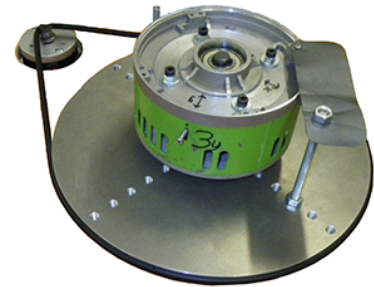

(a)

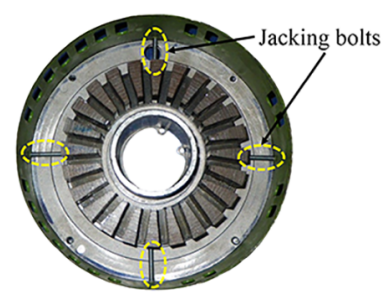

(b)
Figure 2. (a) Fractional hp AFPM motor and special experimental set-up for varying static eccentricity and measuring cogging torque. (b) Four jacking bolts at 90 degree intervals are used to adjust the eccentricity by manipulating the stator position.

is achieved and then the synchronous reactance $X_{s}$ can be calculated from:

$$
I_{s c}=\frac{V_{o c}}{\left|j X_{s}+R_{s}+j X_{e x}+R_{e x}\right|},
$$

where $R_{s}$ is the stator winding resistance. $X_{e x}$ and $R_{e x}$ are the external reactance and resistance, respectively. $X_{e x}$ is negligible for the case under study.

For IPM machines with saliency, such as the spoke motor considered in the exemplified case study, the reluctance is not uniform such that for the flux flowing through the direct axis, the air-gap is longer than the flux flowing through the quadratic axis. This results in smaller d-axis inductance. Synchronous reactance, $X_{s}$, in (1) can be replaced by the daxis synchronous reactance $\left(L_{d}\right)$ for salient-rotor machines.

Equation (1) employs the voltage from open-circuit test and the current from short-circuit test. Therefore, this synchronous reactance calculation approach may be regarded as an open for debate approximation; the non-linear electromagnetic field conditions and the flux pattern are largely different between open-circuit and short-circuit operation which impacts the results. This is particularly important for the study at hand that deals with small deviations.

Example of circuit schematics and virtual test results under the specified IEEE Std 1812 conditions, of open and short circuit are represented for the spoke IPM motor with ferrites in Figs. 3 and 4. These studies are performed at $6000 \mathrm{rpm}$ and several electrical cycles were simulated in order to accommodate the numerical transients and reach steady-state.

The IEEE Std 1812 testing guide, section 4.2.3, defines it as the difference of the maximum to minimum peak torque measured over one complete revolution while machine is on open-circuit and rotated at a very low constant speed of about $3 \mathrm{rpm}$. The low constant speed is specified in order to avoid the rotor inertia, windage and friction effects on the measured data. The cogging torque for the machine with 18-slot 16pole is, in line with expectations, very low, under $2 \%$ of the rated value, as shown in Fig. 3b. A third case study included in the paper, employs an axial flux motor and focuses on cogging torque measurements. A special experimental fixture is employed in order to produce a controlled static eccentricity between the stator and the rotor and the tests are performed according to the IEEE Std 1812. 


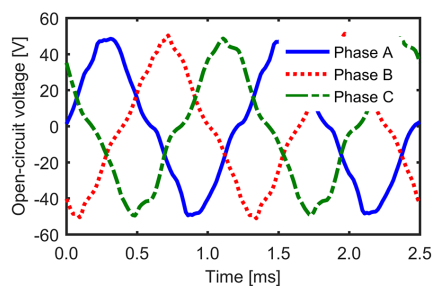

(a)

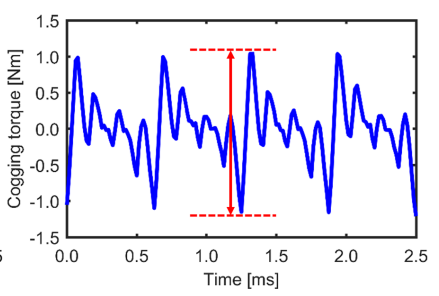

(b)
Figure 3. Open-circuit virtual test results for a spoke-type PM machine case study. (a) Per phase voltages, (b) cogging torque, which in line with expectations for this $18 / 16$ slot/pole combination, is only approx. $2 \%$ of the rated value.

\section{CASE Studies FOR Dimensional And MATERIAL TOLERANCES}

In typical engineering practice, the experimentally measured performance of a new prototype electric machine may differ from design calculations and simulations. Provided that the numerical work has been conducted with well established procedures and software, such as high-fidelity FEA that has been proven in many previous instances to yield satisfactory agreement with experiments both in terms of values and trends on other electric machines of the same type, questions are raised regarding the actual prototype hardware. More specifically, in this case, there is a need to identify any possible out of specification manufacturing and material properties tolerances that would represent the root cause for the noted differences.

In manufacturing practice, test performance may occasionally lie outside the specified tolerance bands, in which case the identification of the root causes is required based on a combination of theoretical and experimental methods. The current study addresses such issues, discusses the suitability of the IEEE Std 1812 procedures for these purposes, and exemplifies possible solutions on three case studies.

The first study is represented by an IPM spoke type radial flux machine with many possible tolerances for the geometrical specifications and magnetic material properties. This machine type was optimally designed with a record breaking high torque density of $12.2 \mathrm{Nm} / \mathrm{kg}$, for application in Formula E racing cars and has an extremely high electrical and magnetic loading [15], [16]. It is a $100 \mathrm{hp}$ motor with a spoke-type rotor containing 16 rare-earth (SmCo) PM poles and 18 slots, which has been successfully manufactured and tested. The associated FE models, such as those exemplified in Fig. 5, have been satisfactorily validated against experimental measurements as previously reported in [15], [16].

A second case study employs the exact same dimensions as the first one, but with the only exception that it uses ceramic ferrites in order to investigate the spoke-type motor's performance at a more typical level of electromagnetic loading. The open-circuit voltage, open-circuit losses, shortcircuit current, and d-axis inductance are the three performance indices considered for the first two case studies.

The eleven geometrical input design variables considered in the first two studies are represented in Fig. 6 and specified in Table I. A tolerance of $\pm 0.1 \mathrm{~mm}$, typical for laser cutting prototyping, has been considered. In this paper, a tolerance of $\pm 5 \%$ is considered for the PM remanence in order to account for possible variations both in the material grade and in the external magnetization for prototypes. The specified material for the laminated core is M19 laminated silicon steel. As an example of deviation from the original specifications, an extreme case of inadvertently employing M43 with the same gauge is considered (see Table II.)

The third case study is devoted to an AFPM machine with 20 surface mounted poles and 24 slots. The topology and magnetic flux distribution are represented in Fig. 7. In axial flux machines, the stacked-up manufacturing tolerances may lead to eccentricity, non-parallel discs resulting in a non-uniform air-gap, non-circular stator and rotor, and any combination of these.

In the studied machine, all geometrical dimensions and magnetic material properties were carefully selected to have nominal values. The tape wound stator is fixed with four bolts to an aluminum stator backing plate in which the rotor bearings are also housed [17]. Due to the specific mounting, the stator may be potentially offset with respect to the rotor, a situation referred to as static eccentricity (Fig. 8). The likelihood of a non-parallel and non-circular rotor were minimized by machining the backing plate and the rotor.

Stator eccentricity, which leads to changes in air-gap flux density, is likely to affect the EMF and cogging torque. It was observed that, in line with expectations, for the machine studied, the open circuit voltage amplitude measured as per the IEEE Std 1812 guidelines is only marginally influenced by the static eccentricity. The effect of eccentricity on the back EMF may be observed by employing search coils, additional windings, and modifications of the machine and/or drive system [18]-[20]. This study aims at using the simplest and widely accepted tests as specified by the IEEE Std 1812, and hence additional coils and modifications were not considered. Therefore, only cogging torque variations with static eccentricity were investigated in more detail.

The third case study, which only involves one input variable, stator to rotor static eccentricity, and one output performance index, cogging toque, includes practical systematic experimentation conducted based on the IEEE Std 1812 test procedures. For the corresponding virtual tests, it should be noted that satisfactory cogging torque agreement between FEA and measurements was previously reported for this machine [17], [21]-[23].

\section{Analytical Prediction of the EfFect of Manufacturing Tolerances ON DESIGN VARIABles}

According to the conventional theory, the open-circuit voltage, $V_{o c}$, of a PM synchronous machine can be analytically estimated as [24]

$$
\begin{aligned}
V_{o c}=2 \pi f_{1} \lambda_{m o}, \lambda_{m o} & =\frac{2}{\pi} k_{w 1} N_{t} k_{v g} \alpha_{i} B_{g o} \tau_{p} L_{F e}, \\
B_{g o} & =\frac{B_{r}}{\frac{\alpha_{i}}{k_{\sigma}} \frac{\tau_{p}}{k_{b} h_{p m}}+\frac{2 \mu_{m r} k_{c} k_{s o} g}{k_{h} w_{p m}}},
\end{aligned}
$$

where $f_{1}$ is the fundamental frequency; $\lambda_{m o}$, the open-circuit magnetizing flux linkage; $k_{w 1}$, the fundamental winding factor; $N_{t}$, number of turns per phase; $k_{v g}$, the ratio between 


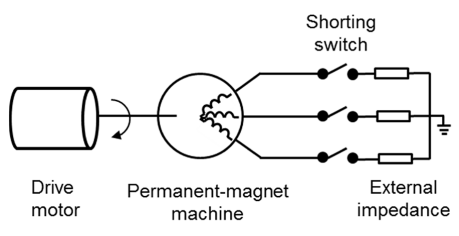

(a)

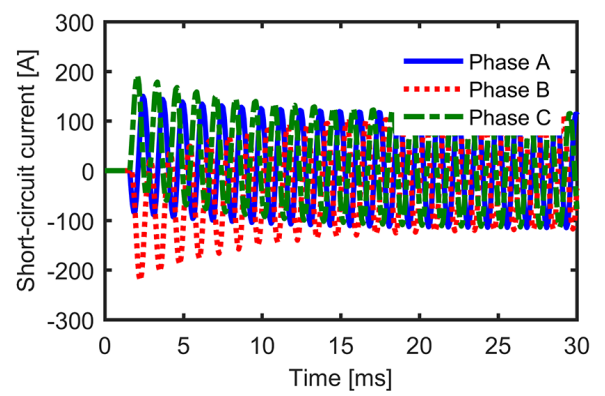

(c)

Figure 4. Short-circuit virtual test implementation and example results. (a) Circuit diagram as per IEEE Std 1812 [13], (b) the equivalent external circuit implemented within the ANSYS Electronics Desktop environment for use with the Maxwell electromagnetic FEA software; the shorting switch is set to close at $1.5 \mathrm{~ms}$, (c) short-circuit current reaching steady-state.

the amplitude of the fundamental wave and the average value of the air-gap flux density; $B_{g o}$, the peak value of the opencircuit flux density; $\tau_{p}$ pole pitch; and $L_{F e}$, the core length; $h_{p m}$ and $w_{p m}$, the PM height and width (length in the direction of magnetization), respectively; $\alpha_{i}$, the pole-arc to pole-pitch ratio; $g$, the air-gap length; $k_{c}$, Carter's coefficient; $\mu_{m r}$, the relative permeability of the $\mathrm{PM} ; k_{s o}$, the d-axis saturation factor at open-circuit operation; and $k_{\sigma}$, is the leakage coefficient estimated at $0.9-1$ - the lower values corresponding to the IPM and the upper ones to the SPM . The coefficient $k_{b}$ is equal to the number of PMs which provide the polar flux: 2 for IPM and 1 for SPM. The coefficient $k_{h}$ is equal to the number of times for which the medium length flux line is passing through the PMs: 1 for IPM and 2 for SPM. It should be noted that, as per (2), open-circuit voltage, $V_{o c}$, is directly proportional to air-gap flux density and inversely proportional to the airgap length. Among the variables under study, represented in Table I and II, remanence and PM dimensions can influence $B_{g o}$. Since dimensional variations have secondary effects on $V_{o c}$, it is expected that the impacts of $B_{r}$ and $g$ are more considerable.

Core losses, $W_{F e}$, are proportional to

$$
W_{F e} \propto k_{h} f_{1} B^{\alpha}+k_{e} f_{1}^{2} B^{2},
$$

where $k_{h}$ and $k_{e}$ are the hysteresis and eddy current coefficients for the laminated steel. The coefficient $\alpha$ has values between $1.5-2.5$, and $B$ is the peak value of flux density in the core, which depends on the flux density in the air-gap (1). Hysteresis and eddy current coefficients are highly dependent on lamination material properties, hence any deviation from specified lamination material will result in inconsistency in

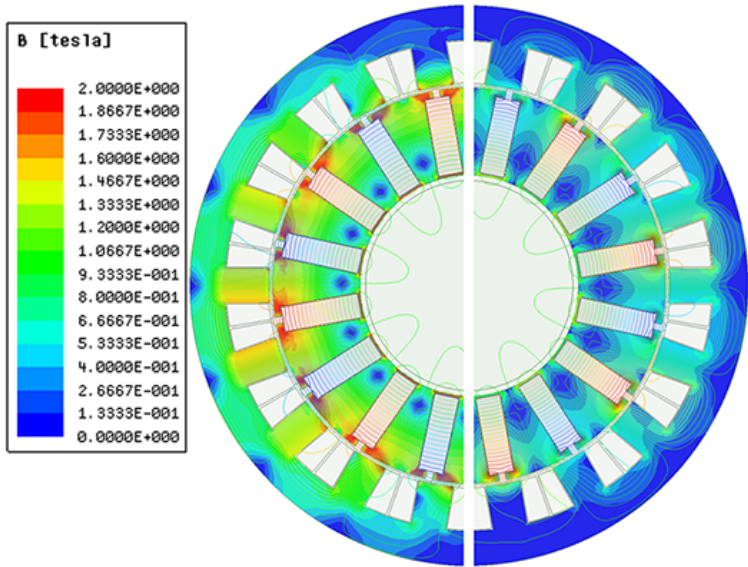

Figure 5. Flux density distribution and flux lines for the $1^{\text {st }}$ and $2^{\text {nd }}$ case studies: the spoke-type motor with high-energy rare-earth SmCo magnets (left) and the same design but with ceramic ferrite magnets (right).

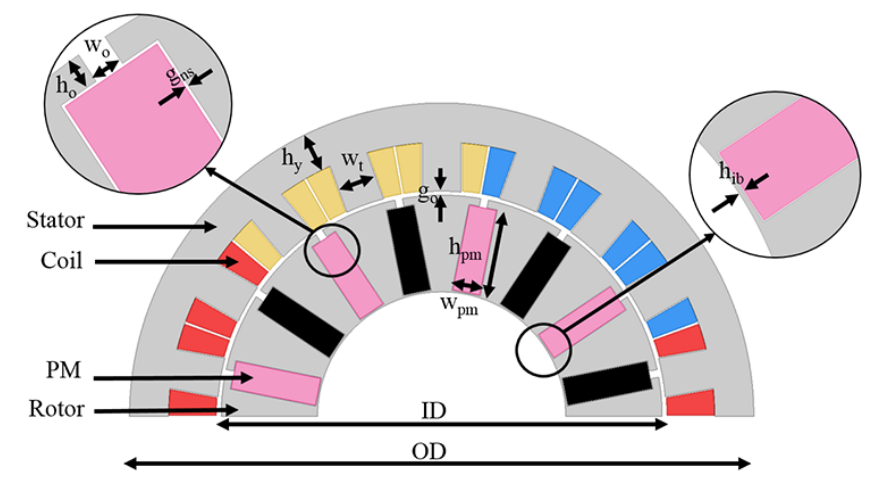

Figure 6. Overview of the geometrical design variables for the $1^{\text {st }}$ and $2^{\text {nd }}$ case studies. The model was analyzed with the ANSYS Maxwell software.

Table I

GEOMETRICAL VARIABLES (FIG. 6). A TOLERANCE OF \pm 0.1 MM FOR GEOMETRICAL VARIABLES HAS BEEN CONSIDERED.

\begin{tabular}{llr}
\hline Geometrical factors & Reference spec. [mm] \\
\hline$x_{1}=O D$ & Outer diameter & 160 \\
$x_{2}=h_{y}$ & Yoke length & 10 \\
$x_{3}=w_{t}$ & Tooth width & 10 \\
$x_{4}=h_{i b}$ & Bridge height & 0.5 \\
$x_{5}=g_{o}$ & Air-gap & 1 \\
$x_{6}=h_{o}$ & Slot opening depth & 3 \\
$x_{7}=w_{p m}$ & PM width & 7 \\
$x_{8}=h_{p m}$ & PM height & 22 \\
$x_{9}=w_{o}$ & Slot opening width & 2 \\
$x_{10}=I D$ & Inner diameter & 115 \\
$x_{11}=g_{n s}$ & Nuisance gap & 0.2 \\
\hline
\end{tabular}

Table II

SMCO RARE-EARTH MAGNETS AND CERAMIC FERRITES WITH A NOMINAL REMANENCE OF $1.1 \mathrm{~T}$ AND $0.4 \mathrm{~T}$, RESPECTIVELY, HAVE BEEN STUDIED TOGETHER WITH THE POSSIBLE INADVERTENT SUBSTITUTION OF THE LAMINATION GRADE.

\begin{tabular}{llcl}
\hline Magnetic & material factors & Reference & Tol./sub. \\
\hline$x_{12}: B_{r}$ & PM remanence & Nom. & $\pm 5 \%$ \\
$x_{13}: M$ & Lamination & M19 & M43 \\
\hline
\end{tabular}

nominal and actual core losses. Moreover, any variable that 


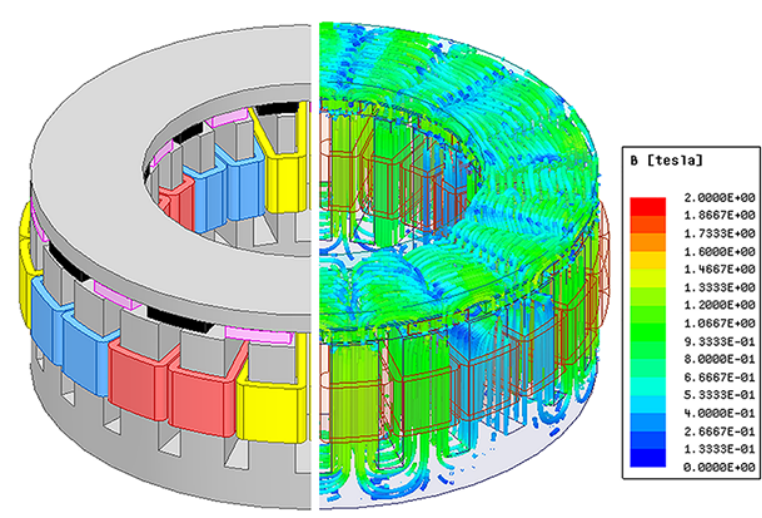

Figure 7. The solid model and the magnetic flux distribution for the $3^{\text {rd }}$ case study, which is an axial flux PM (AFPM) machine.

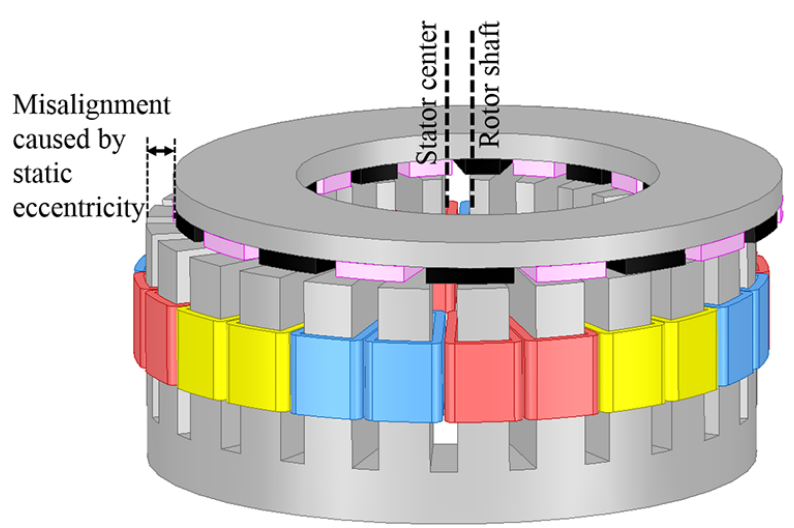

Figure 8. Schematic exaggerated illustration of the static eccentricity considered in the $3^{\text {rd }}$ case study of the AFPM machine.

affects magnetic flux density in the core, including remanence and air-gap, can potentially result in deviations in core losses.

The d-axis inductance, $L_{d}$, may be estimated by [24]

$$
\begin{aligned}
L_{d} & =\frac{2 m \mu_{0}\left(k_{w 1} N_{t}\right)^{2} \tau_{p} L_{F e}}{\pi^{2} p k_{c} g} \cdot \frac{k_{a d}}{k_{s d}}, \\
k_{a d} & =\frac{k_{c} g}{k_{c} g+\frac{k_{h}}{2} \frac{w_{p m}}{\mu_{m r}}},
\end{aligned}
$$

where $m$ is the number of phases; $p$, the number of pole pairs; and $k_{s d}$, d-axis saturation coefficient. Based on (4), it is expected that $L_{d}$ inductance depends on dimensional variables such as $g$ and $w_{p m}$, and only indirectly depends on the laminated steel and PM characteristics through the saturation factors. In the definition of $k_{a d}, g$ is weighted by Carter's coefficient while the effect of $w_{p m}$ is mitigated. Hence, a larger sensitivity of $L_{d}$ to $g$ than to $w_{p m}$ is expected.

Equations (2), (3), and (4) may be used to conduct systematic analytical DOE and sensitivity analysis. Detailed DOE and sensitivity analysis from analytical calculations in comparison to numerical results are provided in section $\mathrm{V}$.

The cogging torque can be estimated from the co-energy in the following,

$$
T=\frac{\partial W_{c}}{\partial \theta}=\frac{1}{2} i^{2} \frac{d L}{d \theta}+N i \frac{d \phi_{m}}{d \theta}-\frac{1}{2} \phi_{m}^{2} \frac{d \Re}{d \theta},
$$

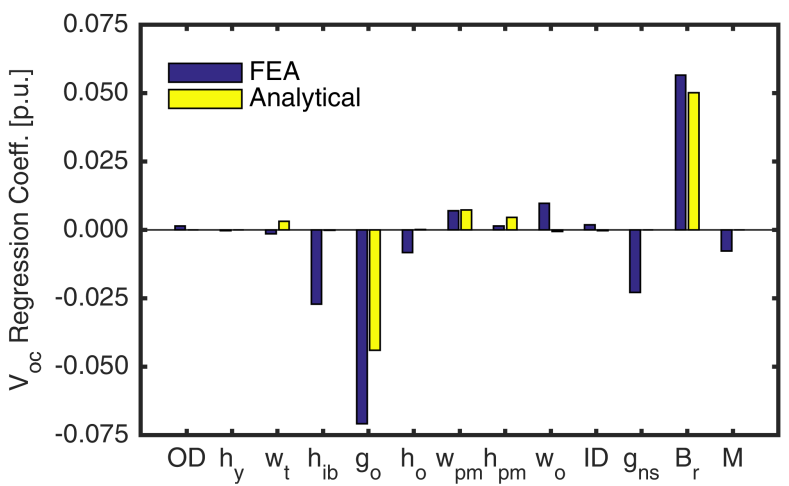

(a)

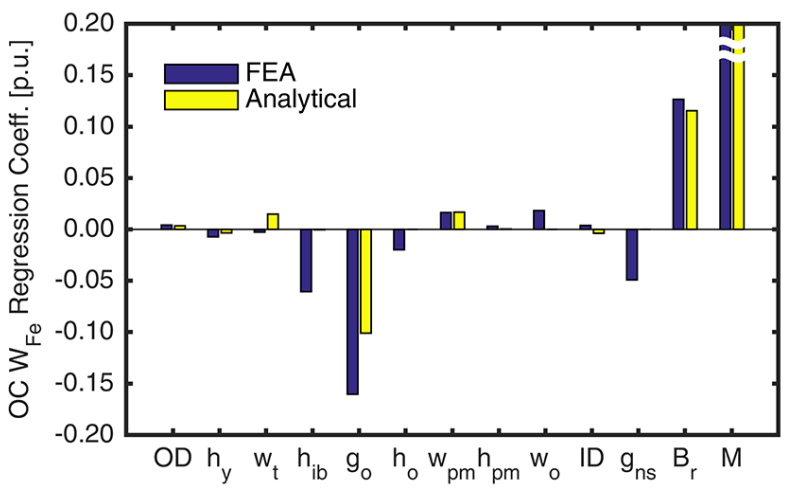

(b)

Figure 9. The per unit regression coefficients calculated for open-circuit based on FEA virtual tests (darker shade bars) and analytically (lighter shade bars) for the motor with ceramic ferrite magnets; (a) back emf, i.e. voltage, (b) core losses. Note the different scales on the y-axis. The bar corresponding to lamination material , $\mathrm{M}$, in (b) is truncated as it reaches up to 0.23 for FEA and 0.3 for analytical simulations, respectively.

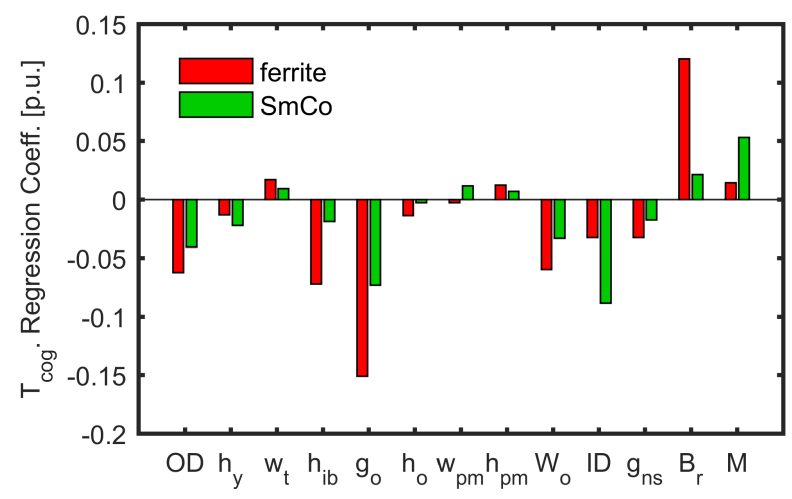

Figure 10. The per unit regression coefficients for cogging torque calculated based on the FEA virtual tests for the spoke machine with ferrite and SmCo magnets.

where $T$ is the electromagnetic torque; $W_{c}$, the co-energy; $\theta$, the rotor position; $i$, the current; $L$ and $N$, the coil inductance and number of turns; $\phi_{m}$, the magnetic flux; and $\mathfrak{R}$, the reluctance. For cogging torque on open circuit, the current is zero, and this provides,

$$
T_{\text {cogg }}=-\frac{1}{2} \phi_{m o}^{2} \frac{d \Re}{d \theta},
$$




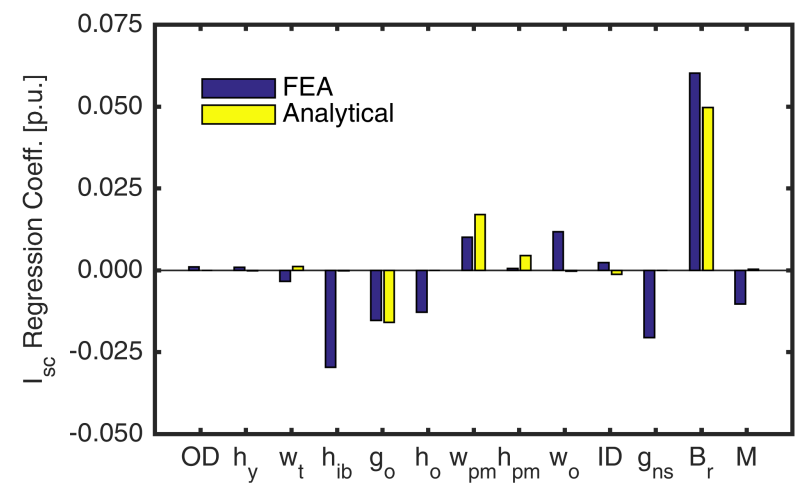

(a)

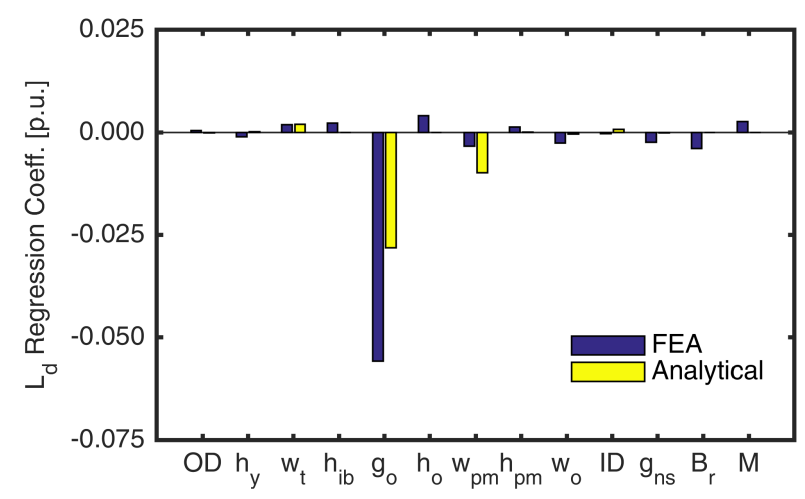

(b)

Figure 11. The per unit regression coefficients calculated for short-circuit based on FEA virtual tests (darker shade bars) and analytical (lighter shade bars) for the motor with ceramic ferrite magnets; (a) d-axis inductance, (b) current. Note the different scales on the y-axis.

where $T_{\text {cogg }}$ is the cogging torque and $\phi_{m o}$ is the air-gap flux at open-circuit. Owing to the dependence of cogging torque on the flux and reluctance of the magnetic circuit, it is expected that magnet remanence, air-gap length, eccentricity and other geometric variables such as the slot opening, diameter, and the skew angle have an effect on it.

\section{Comprehensive Study Based on Design of EXPERIMENTS (DOE) AND VIRTUAL TESTS}

A main objective of the DOE studies is to establish the motor performance sensitivity to varying dimensions and material properties due to manufacturing tolerances, in order to be able to determine the causes of out of specification performance. Data for the two case studies was provided by virtual tests, i.e. FEA simulations of the open and short circuit tests for the spoke PM machine designs.

This approach was preferred due to the very large effort associated with the large number of independent variables and performance indices requiring hundreds of experiments, and is directly supported by the satisfactory validation previously reported by the authors [15], [16]. The analysis was also made possible by the use of a widely accepted and employed FEA software [14] and by the general advancements in modeling and the satisfactory agreement between simulations and measurements previously reported both for values and trends by
Table III

Theoretical MAXIMUM VARIATIONS FOR THE OPEN-CIRCUIT VOLTAGE (BACK EMF) AND CORE LOSSES.

\begin{tabular}{lllrrr}
\hline Performance & & Magnet & Ref. & Min & Max \\
\hline \multirow{2}{*}{$V_{O c}$} & \multirow{2}{*}[\mathrm{V}]{} & ferrite & 51 & 41 & 62 \\
& & SmCo & 133 & 116 & 150 \\
\hline \multirow{2}{*}{$O C W_{F e}$} & \multirow{2}{*}[\mathrm{W}]{} & ferrite & 117 & 77 & 223 \\
& & SmCo & 861 & 641 & 1456 \\
\hline
\end{tabular}

the authors themselves and by other research groups, such as for example for losses [25]-[31], ripple and cogging torque [32], [33], vibration and acoustics [34], temperature distribution [35], high frequency harmonic effects of electromagnetic interference (EMI) [36], and other topics, covered in, for example [37]-[40].

The first step in the DOE procedure includes the definition of the factors and their levels. Figure 6 shows 11 geometrical variables to capture the possible manufacturing deviations. In addition, magnet and laminated steel grades can also be affected by manufacturing tolerances. Hence, overall 13 factors are considered (Table I and II). In order to ensure that all possible non-linearities are taken into account, geometrical factors and remanence are evaluated in three levels. The lamination grade is specified to be M19. Prototype manufacturing variations and material substitutions, due to unavailability or inadvertence, may further degrade the properties to those of M43. Hence 2 levels are considered for $M$.

A full factorial design will result, in the first two cases, in more than a million experiments, i.e. 1,062,882, per case which would be prohibitive even for FEA, let alone for costly hardware experimentation. Instead, a fractional factorial method, which only requires 376 experiments per study case, was preferred making at least virtual prototyping and testing with FEA parametric models and scripting possible for sensitivity analysis with reasonable time and computational resources.

The response variables chosen for the DOE study include from the open-circuit test, the voltage (back emf) and core losses and from the short-circuit test, the current and the daxis inductance. As per (1), unlike the measured short circuit current, the calculated d-axis inductance is correlated with the open-circuit voltage, which has implications in terms of the DOE mathematical formulation, i.e., the response variables must be independent. This is not the case for $L_{d}$, the evaluation of which is based on the recommended method for calculating $X_{s}$ (1). Therefore, it is preferred to directly use $I_{s c}$ as one of the performance parameters rather than $L_{d}$.

The sensitivity analysis is executed by fitting a regression 


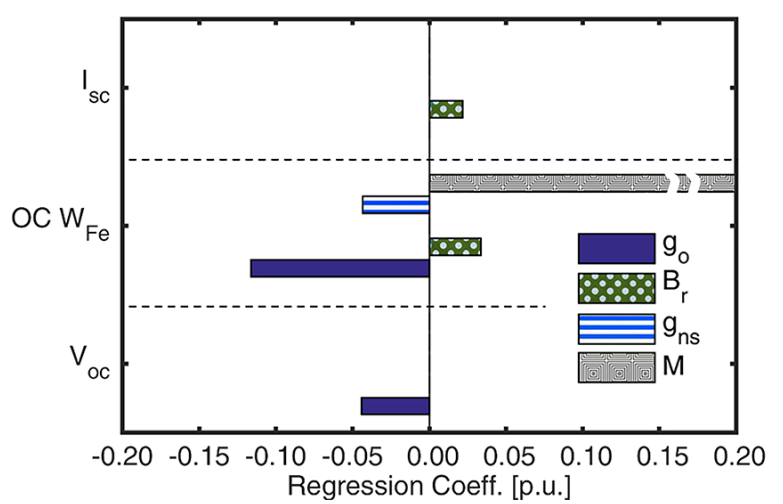

(a)

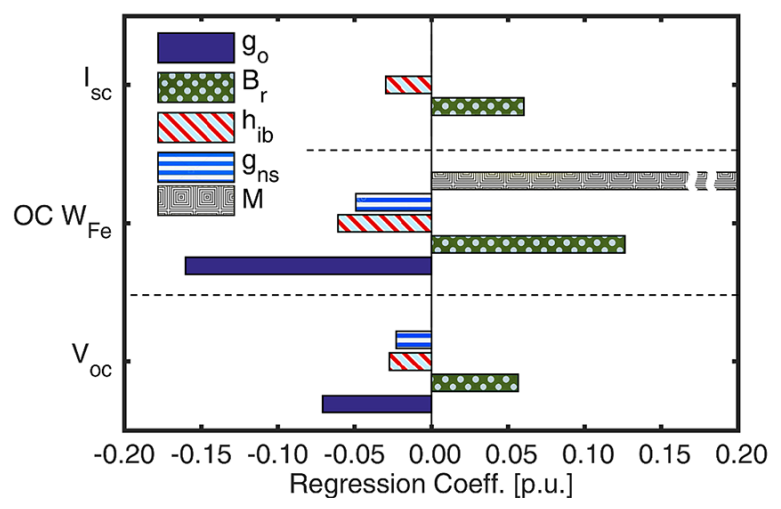

(b)

Figure 12. The per unit regression coefficients for the input factors most significantly affecting the output performance. Results based on FEA virtual tests for the spoke-type motor with (a) rare earth SmCo magnets, and (b) ceramic ferrite magnets.

curve demonstrated by a polynomial function as

$$
\begin{gathered}
Y=\beta_{0}+\sum_{i=1}^{d_{\nu}} \beta_{i} X_{C i}+\sum_{i=1}^{d_{\nu}} \beta_{i i} X_{C i}^{2}+ \\
\sum_{i=1}^{d_{\nu}} \sum_{j=i+1}^{d_{\nu}} \beta_{i j} X_{C i} X_{C j}, \\
X_{C i}=\frac{x_{i}-\left(x_{i, \max }+x_{i, \min }\right) / 2}{\left(x_{i, \max }-x_{i, \min }\right) / 2} ; i=1,2, \ldots, d_{\nu},
\end{gathered}
$$

where $Y$ is a response parameter; $\beta$, the regression coefficient; $d_{\nu}$, the number of factors (13 in this case), $x_{i}$, the $i^{t h}$ input factor; and $X_{C i}$, the normalized (coded) value of the $i^{\text {th }}$ factor. Factors may be normalized as shown in (7). $X_{C i}=$ 0 represents the specified values of the factors with zero manufacturing error, and $\beta_{0}$ is a representation of response parameter in this reference situation. $\beta_{i i}$ and $\beta_{i j}$ illustrate second order effects and interaction between the factors.

A preliminary second order regression model is fit and it was observed that for this study the interaction and higher order terms are negligible. Accordingly, the regression model is modified to fit a first order function. The regression coefficients are estimated using least-squares method. As an instance, $V_{o c}$, obtained from numerical analysis of the model with ferrite
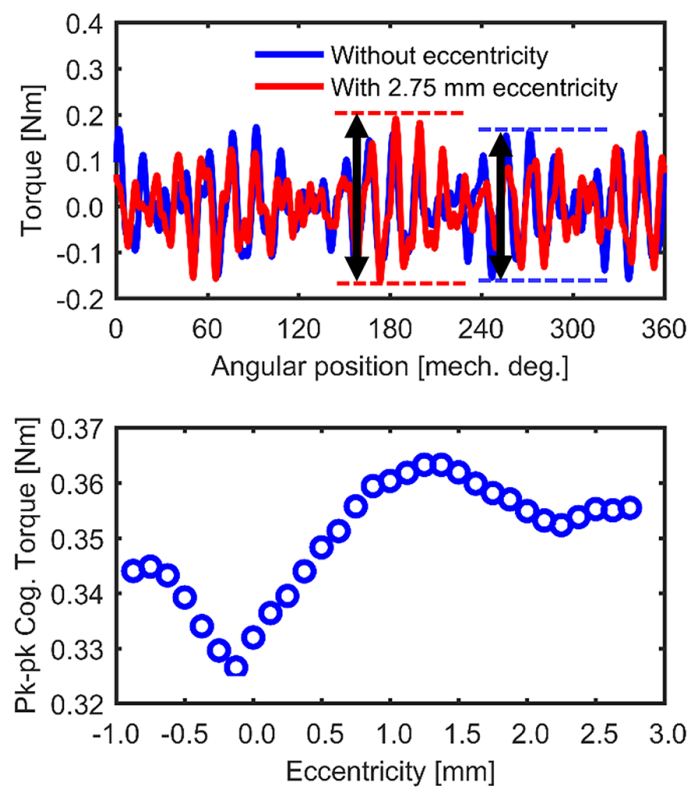

Figure 13. Example cogging torque measurements with and without eccentricity. The top figure illustrates the effects on the harmonics spectrum as well as on the peak-peak values. The peak-peak cogging torque versus eccentricity is depicted at the bottom and a nonlinear relationship is observed. The measurements are performed for a range of positive and negative relative misalignment.

magnets can be estimated using the polynomial function,

$$
\begin{aligned}
Y_{\left(V_{o c}\right)} & =54.06+0.08 X_{C 1}-0.02 X_{C 2}-0.08 X_{C 3}- \\
& 1.47 X_{C 4}-3.83 X_{C 5}-0.45 X_{C 6}+0.38 X_{C 7}+ \\
& 0.08 X_{C 8}+0.52 X_{C 9}+0.10 X_{C 10}-1.24 X_{C 11}+ \\
& 3.06 X_{C 12}-0.42 X_{C 13} .
\end{aligned}
$$

When SmCo magnets are used $\beta_{0}$ is increased from 54.06 to 146.83 , indicating higher open-circuit voltage, as expected.

Per unit regression coefficients, defined as $\frac{\beta_{i}}{\beta_{0}}$ for the $i^{\text {th }}$ factor, represent the percentage of variation in the response when all factors are according to specifications $\left(X_{C j}=0 ; j=\right.$ $\left.1,2, . . i-1, i+1, \ldots d_{v}\right)$ except for one factor which is at its maximum studied deviation $\left(X_{C i}=1\right)$. For instance, the p.u. regression coefficient of $g_{o}$ for $V_{o c}$ is -0.07 . This means that if $g_{o}=1.1 \mathrm{~mm}$ rather than its specified value of $1 \mathrm{~mm}$ and all other variables are according to specifications, $V_{o c}$ would be $1-0.07=0.93$ times its rated value. Therefore, negative regression coefficients indicate that the response reduces upon increase in the corresponding factor. The larger the magnitude of the regression coefficients in Figs. 9-11, the more influential the factor. The regression coefficients of the cogging torque in Fig. 10 are calculated using FEA evaluations.

Some important observations from Figs. 9-11 are:

1) Numerical analysis indicates that the output response parameters are more significantly sensitive to variations of the air-gap, $g_{o}$, remanence, $B_{r}$, bridge height, $h_{i b}$, and nuisance gap, $g_{n s}$, as well as the lamination grade. The impact of the rest of the factors is negligible.

2) The effects of $h_{i b}$ and $g_{n s}$ are not fully captured in the analytical studies. The changes in these two factors affecting saturation and leakage flux, have second order effects on 
performances, which can only be poorly estimated analytically.

3) Lamination material has an observable effect only on the core losses.

4) Open-circuit core loss is very sensitive. This may be understood by considering that while EMF is proportional to the flux density, core loss is proportional to its square (3), thus explaining its higher sensitivity to all variables that may affect flux density.

5) Most of the manufacturing tolerances impact the cogging torque. Therefore, for this machine, studying cogging torque in order to distinguish out of design specification variables is not beneficial, unless the cogging torque is the only performance with deviations, in which case factors that also influence other responses can be assumed to be within specifications, i.e., only $O D, I D$, and $W_{o}$ may be out of design specifications.

This machine at a different magnetic loading is also studied by replacing ferrite magnets with rare earth SmCo magnets. A comparison between regression coefficients of only significant factors, with values above 0.02 p.u., for the motor with ferrite and rare earth magnets is plotted in Fig. 12. The performance parameters of the motor with stronger magnet grade (rare earth magnets), Fig. 12a, represents lower sensitivity to changes in input variables, and negligible sensitivity to $h_{i b}$ and $g_{n s}$. This motor operates under an exceptionally high magnetic loading such that the rotor core is saturated at the inner diameter. Therefore, for instance, a larger bridge height does not result in higher leakage flux and hence output performance is not considerably affected by its variations.

Another outcome of the regression models can be estimating the range within which a performance parameter may vary due to manufacturing tolerances. The limits of this variation are established by consideration of the improbable scenarios where all geometrical and magnetic variables are at their maximum or minimum value within the studied ranges, such that they cause either a cumulative reduction or increase in the value of a performance index. Table III represents these ranges for open-circuit voltage and core losses. The relatively tighter ranges noted for the motor with rare earth PMs is partially due to the stronger saturation of the magnetic circuit bridges, which minimizes flux leakage and reduces performance variability.

\section{EXPERIMENTAL STUdy OF ECCENTRICITY EFFECT ON Cogging Torque}

The third case study involves a $3 \mathrm{Nm}$ rated AFPM surface PM machine with a stator and rotor manufactured with very tight tolerances and with the main design variables selected as close as possible to their nominal values. Experimentation was conducted using only one stator and one rotor and controlling through a special mechanical fixture, as shown in Fig. 2, the static eccentricity, which may cause variations in the back EMF and cogging torque.

In line with expectations for a machine with a large equivalent electromagnetic airgap, as it is the case for surface $\mathrm{PM}$ rotor designs, these variations in the back EMF due to eccentricity were found to be substantially small and are not reported here due to space constraints. Detection of small signals would require special search coils, or additional windings, or modifications in the machine and/or drive system, as described for example in [18]-[20]. The study of such modifications and post-manufacturing add-ons is beyond the scope of this paper, as the objective is to use the simplest tests as specified by the IEEE Std 1812 .

The studied AFPM motor has a special mechanical construction incorporating four jacking bolts at 90 degree intervals in order to allow the adjustment of the stator position and create controlled eccentricity, as shown in Fig. 2b. The test rig has the capability for minor adjustments of the rotor in order to eliminate any possible angular misalignment. Eccentricity of the stator with respect to the rotor was created, while ensuring parallel axial alignment, for 30 cases, up to 2.75 $\mathrm{mm}$. As shown in the example measurements from Fig. 13, the eccentricity causes the amplitude modulation of cogging torque, and first and second order side bands.

For such a motor design with 24 slots and 20 surface mounted PM poles the peak-to-peak cogging toque, is, as expected, low at approximately $10 \%$ of the rated torque. Furthermore, the measured variation with eccentricity is very small at approximately $1 \%$, such that special purpose instrumentation is required and the practicality of wide implementation may be limited. Major challenges are also due to the non-linear variation shown in Fig. 13, which makes it difficult to identify the amount of misalignment, e.g. a measured cogging torque of $0.36 \mathrm{Nm}$ can be caused by a misalignment of $0.75 \mathrm{~mm}$ or $1.7 \mathrm{~mm}$.

Detailed examination of the harmonics and side bands may provide further insights into the amount of misalignment and the nature of eccentricity. It should be noted that previously reported simulation techniques with satisfactory experimental agreement, such as, for example, [17], [21]-[23], can serve as a basis for virtual prototype and test developments, which are not included here due to space limitation. A most important outcome of the case study is the confirmation that an out of specification peak-peak cogging torque value, measured as per the procedures incorporated in the IEEE Std 1812 testing guide, would not suffice just by itself in order to detect the nature of the misalignment and specific techniques for cogging torque waveform and further measurements are required in this respect.

\section{DISCUSSION}

In case of the comprehensive case study of the spoke-type machine, sensitivity analysis for responses from open-circuit $-V_{o c}$ and $W_{F e}$ - and short-circuit tests-preferably $I_{s c}$ may be used to indicate possible sources of deviations from the nominal values. Each of these three responses can be more than, less than, or equal to the nominal values. In this section, a systematic approach for interpreting these deviations, with the purpose of identifying possible manufacturing tolerance(s), is introduced.

For the machine with SmCo magnets, regarding Fig. 12a, the relation between factors and response parameters' deviations can be represented in matrix form as, 


\begin{tabular}{ll|c:c:c:c:c|c|} 
& & $\mathrm{g}_{\mathrm{o}}$ & $\mathrm{B}_{\mathrm{r}}$ & $\mathrm{h}_{\mathrm{ib}}$ & $\mathrm{g}_{\mathrm{ns}}$ & $\mathrm{M}$ \\
$\mathrm{I}_{\mathrm{sc}}$ & $\checkmark$ & $\mathrm{N} / \mathrm{A}$ & $\checkmark$ & $\checkmark$ & $\mathrm{N} / \mathrm{A}$ & $\mathrm{N} / \mathrm{A}$ \\
$\mathrm{W}_{\mathrm{Fe}} \times \uparrow \downarrow$ & $\downarrow \uparrow$ & $\uparrow \downarrow$ & $\downarrow \uparrow$ & $\downarrow \uparrow$ & $\uparrow \downarrow$ \\
$\mathrm{V}_{\mathrm{oc}}$ & $\checkmark$ & $\checkmark$ & $\checkmark$ & $\checkmark$ & $\checkmark$ & N/A \\
\hline
\end{tabular}

Figure 14. Example simple scenario for the spoke-type machine with ferrite magnets where only $W_{F e}$ is out of specification. As $I_{s c}$ and $V_{o c}$ comply with the design predictions, the design variables influencing their value are most probably as specified. This leaves lamination grade $M$ the highest possible out of specification tolerance causing discrepancy in $W_{F e}$.

\begin{tabular}{l|c:c|c|c|c|c} 
& $\mathrm{g}_{\mathrm{o}}$ & $\mathrm{B}_{\mathrm{r}}$ & $\mathrm{h}_{\mathrm{ib}}$ & $\mathrm{g}_{\mathrm{ns}}$ & $\mathrm{M}$ \\
\hline $\mathrm{I}_{\mathrm{sc}} \times \uparrow \downarrow$ & $\mathrm{N} / \mathrm{A}$ & $\uparrow \downarrow$ & $\downarrow \uparrow$ & $\mathrm{N} / \mathrm{A}$ & $\mathrm{N} / \mathrm{A}$ \\
$\mathrm{W}_{\mathrm{Fe}} \times \uparrow \downarrow$ & $\downarrow \uparrow$ & $\uparrow \downarrow$ & $\downarrow \uparrow$ & $\downarrow \uparrow$ & $\uparrow \downarrow$ \\
$\mathrm{V}_{\mathrm{oc}} \times \uparrow \downarrow$ & $\downarrow \uparrow$ & $\uparrow \downarrow$ & $\downarrow \uparrow$ & $\downarrow \uparrow$ & $\mathrm{N} / \mathrm{A}$ \\
\hline
\end{tabular}

(a)

\begin{tabular}{c|c|c|c|c|c|}
\cline { 2 - 6 } & $\mathrm{g}_{\mathrm{o}}$ & $\mathrm{B}_{\mathrm{r}}$ & $\mathrm{h}_{\mathrm{ib}}$ & $\mathrm{g}_{\mathrm{ns}}$ & $\mathrm{M}$ \\
\cline { 2 - 6 } $\mathrm{I}_{\mathrm{sc}} \times \uparrow \downarrow$ & $\mathrm{N} / \mathrm{A}$ & $\uparrow \downarrow$ & $\downarrow \uparrow$ & $\mathrm{N} / \mathrm{A}$ & $\mathrm{N} / \mathrm{A}$ \\
$\mathrm{W}_{\mathrm{Fe}} \times \downarrow \uparrow$ & $\uparrow \downarrow$ & $\downarrow \uparrow$ & $\uparrow \downarrow$ & $\uparrow \downarrow$ & $\uparrow \downarrow$ \\
$\mathrm{V}_{\mathrm{oc}} \times \downarrow \uparrow$ & $\uparrow \downarrow$ & $\downarrow \uparrow$ & $\uparrow \downarrow$ & $\uparrow \downarrow$ & $\mathrm{N} / \mathrm{A}$ \\
\cline { 2 - 6 }
\end{tabular}

(b)

Figure 15. Example scenarios for the spoke-type machine with ferrite magnets and illustrations of the simplifications employed in the identification process of non-conformant tolerances. $I_{S c}$ out of specification values necessitates considering $B_{r}$ and/or $h_{i b}$ variations. If the other two geometrical parameters also deviate in the same direction (a), the possibilities of $g_{o}$ and $g_{n s}$ out of spec deviations are low; if they deviate in the opposite direction (b), all or part of the manufacturing tolerances are out of specification.

$$
\left[\begin{array}{c}
\Delta V_{o c} \\
\Delta W_{F e} \\
\Delta I_{s c}
\end{array}\right]=\left[\begin{array}{cccc}
\beta_{v, g_{o}} & 0 & 0 & 0 \\
\beta_{w, g_{o}} & \beta_{w, B_{r}} & \beta_{w, g_{n s}} & \beta_{w, M} \\
0 & \beta_{i, B_{r}} & 0 & 0
\end{array}\right]\left[\begin{array}{c}
\Delta g_{o} \\
\Delta B_{r} \\
\Delta g_{n s} \\
\Delta M
\end{array}\right]
$$

where $\Delta V_{o c}$, is the difference between the measured and the nominal value of $V_{o c}$, i.e., $\Delta V_{o c}=V_{\text {mes }}-V_{\text {nom }} ; \Delta g_{o}$, the normalized deviation of the specified $g_{o}$; and $\beta$, the regression coefficients with the subscripts representing the relevant response and factor, respectively. The rest of the entries in (9) are defined similarly.

Equation (9) represents a system of 3 equations, with 4 unknowns, namely $\Delta g_{o}, \Delta B_{r}, \Delta g_{n s}$, and $\Delta M$. Such a system cannot be solved unless at least one of the unknowns is determined independently. For special scenarios, this might be possible using sensitivity analysis. For clarification, some examples are included below.

The first example is when measured $V_{o c}$ and $W_{F e}$ match with their nominal values, i.e., $\Delta V_{o c}=\Delta W_{F e}=0$ and only $I_{s c}$ deviates, i.e., $\Delta I_{s c} \neq 0$. It can be concluded that all variables influencing $V_{o c}$ and $W_{F e}$ are most probably as designed. Therefore, the only out of specification variable is $B_{r}$. Similarly, in case only $V_{o c}$ deviates, it can be an indication of only $g_{o}$ having out of specification tolerances. However, if only $\Delta W_{F e} \neq 0$, a definite conclusion cannot be reached, as either or both $g_{n s}$ and $M$ may have manufacturing tolerances.

When more than one performance index deviates from design expectations, the certainty of conclusions deteriorate. For instance, if $\Delta W_{F e} \neq 0, \Delta V_{o c} \neq 0$, and $\Delta I_{s c}=0$, only the presence of out of specification tolerance in $B_{r}$ can be eliminated and all the other variables may or may not be as specified by the design.

These examples show that the identification of design tolerances with certainty is possible, if the number of measurable responses equals the number of possible manufacturing tolerances. The narrowing down of the possible factors can be performed with sensitivity analysis and careful study of that particular scenario.

For a larger number of factors, it is more difficult to identify the deviation source(s). Adding another response, such as cogging torque, to such studies is only beneficial if the new response does not add another unknown to the system of equations. In the case study, it was observed that in addition to the factors included in Fig. 12, cogging torque is also influenced by $I D, O D$, and $W_{o}$, three parameters that do not affect other responses. Therefore, inclusion of cogging torque does not contribute additional information which can be used for distinguishing the out of specification design variables. On the other hand, in case cogging torque is the only response with deviation from expectation, it may be concluded that the out of specification variables are limited to those three.

For the case of the spoke machine with ferrite magnets, the number of effective factors increases as seen in Fig. 12b. The relation between response parameters' deviations and design tolerances, can be formulated as

$$
\left[\begin{array}{c}
\Delta V_{o c} \\
\Delta W_{F e} \\
\Delta I_{s c}
\end{array}\right]=\left[\begin{array}{ccccc}
\beta_{v, g_{o}} & \beta_{v, B_{r}} & \beta_{v, h_{i b}} & \beta_{v, g_{n s}} & 0 \\
\beta_{w, g_{o}} & \beta_{w, B_{r}} & \beta_{w, h_{i b}} & \beta_{w, g_{n s}} & \beta_{w, M} \\
0 & \beta_{i, B_{r}} & \beta_{i, h_{i b}} & 0 & 0
\end{array}\right]\left[\begin{array}{c}
\Delta g_{o} \\
\Delta B_{r} \\
\Delta h_{i b} \\
\Delta g_{n s} \\
\Delta M \\
(10)
\end{array}\right]
$$

This represents a system of 3 equations, with 5 unknowns. Such a system cannot be solved unless at least two of the unknowns are determined independently.

In this machine, suppose $\Delta W_{F e} \neq 0, \Delta I_{s c}=\Delta V_{o c}=0$. This scenario is illustrated in Fig. 14. The parameter deviating from the nominal value is marked with $\boldsymbol{X}$, while the parameters and variables matching with the design specifications are marked with $\boldsymbol{V}$. The upward and downward arrows indicate a value larger and smaller than the design specification, respectively. The deviation direction is color coded to separate different cases. The dashed lines represent factors with less likely manufacturing tolerances. Lamination grade $M$ is the only design variable that affects the loss with no measurable impact on the other two parameters. therefore, it can be concluded that $M$ is most probably the only out of specification design variable.

In another example, $\Delta V_{o c}=\Delta W_{F e}=0$ and $\Delta I_{s c} \neq 0$, it follows that the source of deviation cannot be narrowed down with certainty to only tolerances in $B_{r}$ unlike in the previous case; those in $h_{i b}$ also might be present. On the other hand, if only $V_{o c}$ deviates from the nominal value, the possibility of having prototyped the motor with out of specification lamination material can be eliminated, but any of the other four factors or their combinations might exist. 
Another example is when deviations are observed in all three performances indices, such that $\Delta I_{s c}>0, \Delta W_{F e}>0$, and $\Delta V_{o c}>0$. In this case, the possibility of out of specification values of either or both $B_{r}$ and $h_{i b}$ is higher, because these parameters affect all performance indices the same way (Fig. 15a). A different scenario arises if $\Delta I_{s c}>0$, $\Delta W_{F e}<0$, and $\Delta V_{o c}<0$. For example, an increase in $B_{r}$ can cause the increased $I_{s c}$, but not the reduced $W_{F e}$. Due to the dependence of $\Delta W_{F e}$ on other factors information is required. Figure $15 \mathrm{~b}$ is an illustration of this example.

In the study investigating the static eccentricity effects on the cogging torque, it was found that if all other variables are ensured to be according to specified design, deviations in cogging torque may be used as an indication of eccentricity. However, the side bands and harmonics, also influenced, may be examined to obtain more insights about the nature and magnitude of the eccentricity. This requires additional guidelines and expanded cogging torque measurement discussions to those covered in the existing IEEE Std 1812 testing guide.

The examined instance scenarios indicate that identification of out of specification variables strongly depends on the loadings and configuration of the machine. A comprehensive case-by-case sensitivity analysis accompanied by engineering judgment may help in narrowing down the possible manufacturing/prototyping tolerances.

\section{CONCLUSION}

The paper proposes a new systematic method aimed at quantifying the effect of tolerances on PM synchronous machine performance in order to identify possible non-compliant dimensional variables and material characteristics based solely on the results of the open-circuit and short-circuit procedures incorporated in the newly approved IEEE Std 1812 standard, which are independent of the power electronics drive and control. The method is illustrated with three case studies and it is observed that through the combined comparative analysis of different tests, the non-conforming tolerances may be determined in some instances.

While the method itself is generally applicable in scope, it is also shown that, as the electromagnetic loading greatly affects the sensitivity of the test outputs to tolerances, the careful consideration of the individual machine topology is required as part of the studies, limiting the simple generalization of quantitative conclusions. For example, in the first two case studies, which are relevant to early development and prototyping work, and which consider two radial flux IPM motors that are identical with the exception of the permanent magnet type employed, i.e. SmCo and ferrite, the very same tolerances may lead to largely different variations of $\pm 13 \%$ and $\pm 20 \%$, respectively, for the open circuit voltage. Likewise, the same tolerances will result in open circuit core losses ranging from approximately $75 \%$ to $170 \%$ of the nominal design values for the SmCo magnet machine and from $65 \%$ to $200 \%$ for the machine with ferrite magnets.

The last case study, which is relevant to a production setup with tight tolerances, such that the main variability is represented by the eccentricity resultant from the stack-up assembly, considered the output cogging toque. It was shown that the peak-peak value, measured as per the IEEE Std 1812 may not suffice just by itself for determining the type and amount of stator to rotor misalignment. In this case, further investigations, based on the cogging torque harmonics and side bands are recommended.

\section{ACKNOWLEDGMENT}

The support of University of Kentucky, the L. Stanley Pigman endowment and the SPARK program, ANSYS Inc. and Regal Beloit Corp. is gratefully acknowledged.

\section{REFERENCES}

[1] M. Rosu, P. Zhou, D. Lin, D. M. Ionel, M. Popescu, F. Blaabjerg, V. Rallabandi, and D. Staton, Multiphysics Simulation by Design for Electrical Machines, Power Electronics and Drives. Wiley-IEEE Press, 2017.

[2] Y.-K. Kim, J.-P. Hong, and J. Hur, "Torque characteristic analysis considering the manufacturing tolerance for electric machine by stochastic response surface method," IEEE Transactions on Industry Applications, vol. 39, no. 3, pp. 713-719, May 2003.

[3] F. Gillon and P. Brochet, "Screening and response surface method applied to the numerical optimization of electromagnetic devices," IEEE Transactions on Magnetics, vol. 36, no. 4, pp. 1163-1167, Jul 2000.

[4] I. Coenen, M. V. der Giet, and K. Hameyer, "Manufacturing tolerances: Estimation and prediction of cogging torque influenced by magnetization faults," IEEE Transactions on Magnetics, vol. 48, no. 5, pp. 1932-1936, May 2012.

[5] A. J. P. Ortega, S. Paul, R. Islam, and L. Xu, "Analytical model for predicting effects of manufacturing variations on cogging torque in surface-mounted permanent magnet motors," IEEE Transactions on Industry Applications, vol. 52, no. 4, pp. 3050-3061, July 2016.

[6] X. Ge and Z. Q. Zhu, "Sensitivity of manufacturing tolerances on cogging torque in interior permanent magnet machines with different slot/pole number," in 2016 IEEE Energy Conversion Congress and Exposition (ECCE), Sept 2016, pp. 1-8.

[7] M. Balluff, H. Naumoski, and K. Hameyer, "Sensitivity analysis on tolerance induced torque fluctuation of a synchronous machine," in 2016 6th International Electric Drives Production Conference (EDPC), Nov 2016, pp. 128-134.

[8] L. Wu, R. Qu, B. Song, H. Bi, O. Jing, G. Yang, and C. Du, "Analysis of cogging torque in surface permanent magnet machine with manufacturing tolerances," in IECON 2015 - 41st Annual Conference of the IEEE Industrial Electronics Society, Nov 2015, pp. 004 732-004 737.

[9] J. Ou, Y. Liu, R. Qu, and M. Doppelbauer, "Experimental and theoretical research on cogging torque of $\mathrm{PM}$ synchronous motors considering manufacturing tolerances," IEEE Transactions on Industrial Electronics, vol. 65, no. 5, pp. 3772-3783, May 2018.

[10] V. Simón-Sempere, M. Burgos-Payán, and J. R. Cerquides-Bueno, "Influence of manufacturing tolerances on the electromotive force in permanent-magnet motors," IEEE Transactions on Magnetics, vol. 49, no. 11, pp. 5522-5532, Nov 2013.

[11] P. Eklund and S. Eriksson, "Air gap magnetic flux density variations due to manufacturing tolerances in a permanent magnet synchronous generator," in 2016 XXII International Conference on Electrical Machines (ICEM), Sept 2016, pp. 93-99.

[12] N. Taran, V. Rallabandi, D. M. Ionel, and P. Zhou, "On the effect of design tolerances on the performance of synchronous PM machines evaluated according to the IEEE Std 1812," in 2017 IEEE International Electric Machines and Drives Conference (IEMDC), May 2017, pp. 1-7.

[13] "IEEE trial-use guide for testing permanent magnet machines," IEEE Std 1812-2014, pp. 1-56, Feb 2015.

[14] ANSYS Electronics Desktop, version 18.2, 2018.

[15] A. Fatemi, D. M. Ionel, M. Popescu, and N. A. O. Demerdash, "Design optimization of spoke-type pm motors for formula e racing cars," in 2016 IEEE Energy Conversion Congress and Exposition (ECCE), 2016.

[16] A. Fatemi, D. M. Ionel, M. Popescu, Y. C. Chong, and N. Demerdash, "Design optimization of a high torque density spoke-type PM motor for a race drive cycle," IEEE Transactions on Industry Applications, pp. $1-1,2018$. 
[17] M. Thiele and G. Heins, "Identifying cogging torque harmonics affected by misalignment in axial flux fractional pitch PMSM," in 2012 XXth International Conference on Electrical Machines, Sept 2012, pp. 29692974.

[18] K. Kang, J. Song, C. Kang, S. Sung, and G. Jang, "Real-time detection of the dynamic eccentricity in permanent-magnet synchronous motors by monitoring speed and back emf induced in an additional winding," IEEE Transactions on Industrial Electronics, vol. 64, no. 9, pp. 71917200, Sept 2017.

[19] S. M. Mirimani, A. Vahedi, F. Marignetti, and R. D. Stefano, "An online method for static eccentricity fault detection in axial flux machines," IEEE Transactions on Industrial Electronics, vol. 62, no. 3, pp. 19311942, March 2015.

[20] J. Hong, S. B. Lee, C. Kral, and A. Haumer, "Detection of airgap eccentricity for permanent magnet synchronous motors based on the d-axis inductance," IEEE Transactions on Power Electronics, vol. 27, no. 5, pp. 2605-2612, May 2012.

[21] M. Thiele and G. Heins, "Computationally efficient method for identifying manufacturing induced rotor and stator misalignment in permanent magnet brushless machines," IEEE Transactions on Industry Applications, vol. 52, no. 4, pp. 3033-3040, July 2016.

[22] M. Thiele, G. Heins, and D. Patterson, "Identifying manufacturing induced rotor and stator misalignment in brushless permanent magnet motors," in 2014 International Conference on Electrical Machines (ICEM), Sept 2014, pp. 2728-2733.

[23] B. Saunders, G. Heins, F. D. Boer, and M. Thiele, "Cogging torque estimation for sensorless PMSM," in 2012 International Conference on Electrical Machines (ICEM), Sept 2012, pp. 2949-2954.

[24] D. M. Ionel, J. F. Eastham, T. J. E. Miller, and E. Demeter, "Design considerations for PM synchronous motors for flux weakening applications," in 1997 Eighth International Conference on Electrical Machines and Drives (Conf. Publ. No. 444), Sep 1997, pp. 371-375.

[25] D. M. Ionel, M. Popescu, M. I. McGilp, T. J. E. Miller, S. J. Dellinger, and R. J. Heideman, "Computation of core losses in electrical machines using improved models for laminated steel," IEEE Transactions on Industry Applications, vol. 43, no. 6, pp. 1554-1564, Nov 2007.

[26] D. M. Ionel, M. Popescu, S. J. Dellinger, T. J. E. Miller, R. J. Heideman, and M. I. McGilp, "On the variation with flux and frequency of the core loss coefficients in electrical machines," IEEE Transactions on Industry Applications, vol. 42, no. 3, pp. 658-667, May 2006.

[27] D. Lin, P. Zhou, and A. Bergqvist, "Improved vector play model and parameter identification for magnetic hysteresis materials," IEEE Transactions on Magnetics, vol. 50, no. 2, pp. 357-360, Feb 2014.

[28] P. Zhou, D. Lin, C. Lu, N. Chen, and M. Rosu, "A new algorithm to consider the effects of core losses on 3-d transient magnetic fields," IEEE Transactions on Magnetics, vol. 50, no. 2, pp. 365-368, Feb 2014.

[29] W. Chen, J. Ma, X. Huang, and Y. Fang, "Predicting iron losses in laminated steel with given non-sinusoidal waveforms of flux density,"
Energies, vol. 8, no. 12, pp. 13 726-13 740, 2015. [Online]. Available: http://www.mdpi.com/1996-1073/8/12/12384

[30] A. Fatemi, D. M. Ionel, N. A. O. Demerdash, D. A. Staton, R. Wrobel, and Y. C. Chong, "A computationally efficient method for calculation of strand eddy current losses in electric machines," in 2016 IEEE Energy Conversion Congress and Exposition (ECCE), Sept 2016, pp. 1-8.

[31] P. Zhang, G. Y. Sizov, J. He, D. M. Ionel, and N. A. O. Demerdash, "Calculation of magnet losses in concentrated-winding permanent-magnet synchronous machines using a computationally efficient finite-element method," IEEE Transactions on Industry Applications, vol. 49, no. 6, pp. 2524-2532, Nov 2013.

[32] D. M. Ionel, M. Popescu, M. McGilp, T. J. E. Miller, and S. Dellinger, "Assessment of torque components in brushless permanent magnet machines through numerical analysis of the electromagnetic field," in Conference Record of the 2004 IEEE Industry Applications Conference, 2004. 39th IAS Annual Meeting., vol. 3, Oct 2004, pp. 1715-1722 vol.3.

[33] S. L. Ho, S. Yang, P. Zhou, H. C. Wong, and M. A. Rahman, "A combined finite element-domain elimination method for minimizing torque ripples in inverter-fed ac motor drive systems," IEEE Transactions on Magnetics, vol. 36, no. 4, pp. 1817-1821, July 2000.

[34] D. Torregrossa, F. Peyraut, B. Fahimi, J. M'Boua, and A. Miraoui, "Multiphysics finite-element modeling for vibration and acoustic analysis of permanent magnet synchronous machine," IEEE Transactions on Energy Conversion, vol. 26, no. 2, pp. 490-500, June 2011.

[35] W. Jiang and T. M. Jahns, "Coupled electromagnetic-thermal analysis of electric machines including transient operation based on finite-element techniques," IEEE Transactions on Industry Applications, vol. 51, no. 2, pp. 1880-1889, March 2015.

[36] O. A. Mohammed and S. Ganu, "Fe-circuit coupled model of electric machines for simulation and evaluation of emi issues in motor drives," IEEE Transactions on Magnetics, vol. 46, no. 8, pp. 3389-3392, Aug 2010.

[37] J. Faiz, B. M. Ebrahimi, B. Akin, and H. A. Toliyat, "Comprehensive eccentricity fault diagnosis in induction motors using finite element method," IEEE Transactions on Magnetics, vol. 45, no. 3, pp. 1764 1767, March 2009.

[38] J. Bacher, F. Waldhart, and A. Muetze, "3-D FEM calculation of electromagnetic properties of single-phase induction machines," IEEE Transactions on Energy Conversion, vol. 30, no. 1, pp. 142-149, March 2015.

[39] H. D. Gersem and A. Muetze, "Finite-element supported transmissionline models for calculating high-frequency effects in machine windings," IEEE Transactions on Magnetics, vol. 48, no. 2, pp. 787-790, Feb 2012.

[40] R. Liu, C. C. Mi, and D. W. Gao, "Modeling of eddy-current loss of electrical machines and transformers operated by pulsewidth-modulated inverters," IEEE Transactions on Magnetics, vol. 44, no. 8, pp. 20212028, Aug 2008. 